\title{
La tauromaquia vulnera la Convención sobre los Derechos del Niño
}

Anna Mulà Arribas ${ }^{1}$

\section{La Organización para las Naciones Unidas (ONU) ${ }^{2}$, a través del Comité de} los Derechos del Niño ${ }^{3}$, integrado por 18 expertos en el campo de los derechos de la infancia procedentes de distintos países del mundo, se ha pronunciado de forma expresa en contra de que los niños, niñas y adolescentes menores de 18 años (en adelante niños) participen y asistan a eventos taurinos. Así lo ha expresado el Comité en las observaciones finales dirigidas a Portugal tras el examen del informe presentado por este país para dar cuenta de las medidas

\footnotetext{
${ }^{1}$ Abogada. Asesora legal de la Fundación Franz Weber y coordinadora de "Infancia Sin Violencia". Miembro de la Junta Directiva de la Comisión de Protección de los Derechos de los Animales del Colegio de abogados de Barcelona; Profesora en el Máster en Derecho Animal y Sociedad y miembro del grupo de investigación Animales, Derecho y Sociedad, dirigidos ambos por la Profesora Teresa Giménez-Candela.
}

${ }^{2}$ Las Naciones Unidas son una organización internacional fundada en 1945 tras la Segunda Guerra Mundial integrada actualmente por 193 Estados miembros. Se define como una asociación de gobierno global que facilita la cooperación en asuntos como el mantenimiento de la paz y la seguridad, la prevención de conflictos y la asistencia humanitaria, el desarrollo económico y social, el desarrollo sostenible, la protección de refugiados, la lucha contra el terrorismo, el desarme, la promoción de la democracia, la igualdad entre los géneros, y los derechos humanos, con el fin de alcanzar sus objetivos y coordinar los esfuerzos para un mundo más seguro para las generaciones presentes y futuras. Desde su sede en Nueva York, los Estados miembros y otros organismos vinculados deliberan y deciden acerca de temas significativos y administrativos en reuniones periódicas celebradas durante el año. La sede europea, y segunda sede mundial de la ONU, se sitúa en Ginebra, Suiza http://www.un.org/

${ }^{3}$ El Comité de los Derechos del Niño es el órgano de expertos independientes de la ONU que supervisa la aplicación de la Convención sobre los Derechos del Niño por sus Estados Partes. http://www2.ohchr.org/spanish/bodies/crc/ 
adoptadas para proteger a la infancia en virtud de la Convención sobre los Derechos del Niño ${ }^{4}$.

Para dictar dicho pronunciamiento, el Comité ha tenido en cuenta el interés superior del niño, un principio universal también incorporado en todos los ordenamientos internos de protección de la infancia y la adolescencia, en virtud del cual, el interés superior del niño, en este caso a no ser expuesto a la violencia, prima sobre cualquier otro interés legítimo que pudiera concurrir o entrar en conflicto, como el derecho a participar libremente en la vida cultural.

Esta postura del Comité tiene una repercusión de magnitud mundial, especialmente en los países que como España, todavía no ha tomado medidas para evitar que los niños acudan a espectáculos y eventos taurinos, reciban clases de tauromaquia o participen como toreros.

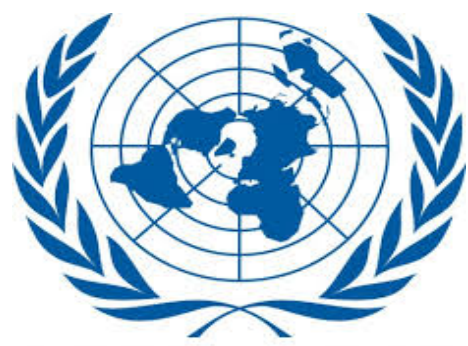

\section{NACIONES UNIDAS}

La Convención sobre los Derechos del Niño fue aprobada por la Asamblea General de las Naciones Unidas el 20/11/1989 y es el tratado internacional que cuenta con más ratificaciones de la historia. En este sentido, la aceptación de la Convención por parte de un número tan elevado de países, refuerza la necesidad de garantizar de forma universal la protección de la infancia.

\footnotetext{
${ }^{4}$ La Convención sobre los Derechos del Niño es un tratado internacional de la ONU de carácter obligatorio y vinculante por el que se reconocen los derechos humanos de las personas menores de 18 años. http://www2.ohchr.org/spanish/law/crc.htm
} 
Los Estados Partes se comprometen en virtud de la Convención a asegurar al niño la protección y el cuidado que sean necesarios para su bienestar y garantizar su desarrollo físico, mental, moral y social, y para ello se deben adoptar todas las medidas administrativas, legislativas, sociales y educativas que sean necesarias, reconociendo expresamente el derecho del niño a la protección contra toda forma de perjuicio o abuso mental, el derecho a la educación compatible con la dignidad humana, la protección contra el desempeño de cualquier trabajo que pueda resultar peligroso para su desarrollo físico, mental, moral o social y el derecho al esparcimiento, al juego y a las actividades recreativas propias de su edad -que no cumplen los eventos taurinos-.

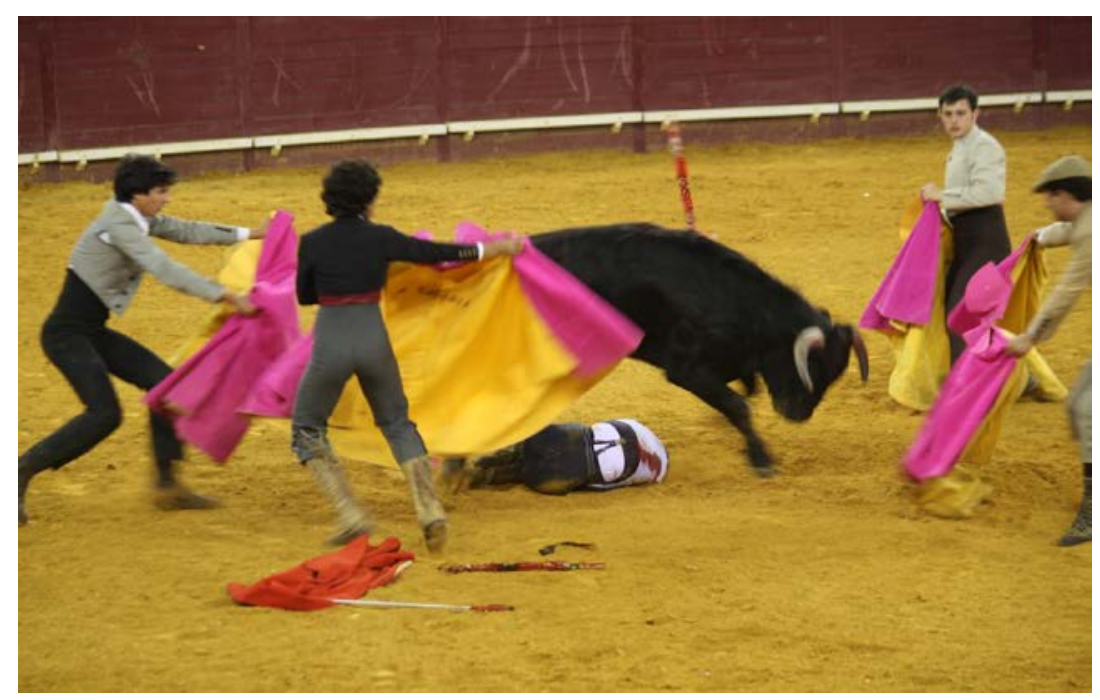

Los países que han ratificado la Convención (entre los que se encuentran los 8 países del mundo donde todavía la tauromaquia es legal: España, Portugal, Francia, Ecuador, Venezuela, México, Colombia y Perú) tienen que rendir cuentas cada 5 años sobre su cumplimiento al Comité de los Derechos del Niño. Para el examen de los informes de los Estados parte sobre las medidas y progresos que vayan adoptando para dar cumplimiento a los derechos reconocidos en la Convención, las organizaciones no gubernamentales (ONG) reconocidas con carácter consultivo ante las Naciones Unidas 
pueden presentar al Comité informes pertinentes y ser invitados a proporcionar asesoramiento, con el fin de asegurar la mejor aplicación posible de la Convención. En este sentido, la Fundación Franz Weber, en el marco de la campaña "Infancia sin violencia", dirigida a proteger a la niñez y a la juventud de la violencia que constituyen los espectáculos taurinos y a reconducir el grave atropello que esto supone a los derechos más elementales de los niños recogidos en la legislación, como pudiera ser la integridad física y psicológica de los niños, asesoró al Comité sobre la violencia física y psicológica a las que están expuestos los jóvenes toreros, los niños que asisten a las escuelas taurinas, los que participan en festejos, los que son espectadores de corridas de toros en directo o a través de medios audiovisuales y los que pudieran recibir una educación taurina en los colegios. Dicha Fundación, con la colaboración de psicólogos expertos en infancia, presentó un informe de investigación detallando en profundidad cuales son las actividades taurinas con niños en Portugal, primer país taurino examinado, y porque dichas actividades vulneran la Convención sobre los Derechos del niño son vulnerados.

Las pre-sesiones y sesiones evaluadoras del Comité se celebran en la Sede de las Naciones Unidas, en Ginebra (Suiza). La pre-sesión de Portugal tuvo lugar los días 22 y 23 de junio de 2013 y una delegación de la Fundación Franz Weber asistió para hacer una breve exposición pública sobre el informe presentado el mes de marzo y someterse a las preguntas de los miembros del Comité, al ser la primera vez que se trataba este tema en dicha Sede. La sesión de Portugal (que fue pública), con asistencia de la delegación del Gobierno de Portugal, tuvo lugar los días 22 y 23 de enero de 2014 y el Comité tuvo la oportunidad de preguntar a la delegación portuguesa que medidas pensaba tomar el Gobierno en esta materia para reconducir la situación en aras a cumplir con la Convención. Durante la sesión examinadora, la vicepresidenta de dicho Comité y representante de Ecuador, Sara Oviedo, expresó que la participación en actividades taurinas de niños supone una "fuerte violación de los artículos de la Convención sobre los Derechos del niño". Hiranthi 
Wijemanne, otro miembro del Comité proveniente de Sri Lanka, expresó su preocupación por esta cuestión argumentando que "Desde pequeño al niño se le expone a una forma de actividad violenta" que además "conlleva riesgos para su propia integridad física". Jorge Cardona, miembro del Comité español, resaltó que "a pesar de que el organismo portugués para la protección de los niños ya dictaminó en 2009 que dicha actividad suponía un riesgo para éstos, a día de hoy se sigue autorizando a menores de edad a participar en espectáculos taurinos, en contra de las obligaciones de la Convención".

Una vez celebrada la sesión con la Delegación del Estado parte que se examina, el Comité redacta un Informe final en el cual formula observaciones y recomendaciones generales basadas en la información recibida por los Estados partes y otras entidades, las cuales se transmiten a los Estados Partes y se notifican a la Asamblea General de Naciones Unidas. Así, el 5 de febrero de 2014, el Comité hizo público su informe en el que se incluyó una importante observación sobre este tema por primera vez en la historia de Naciones Unidas, en el siguiente sentido (de momento únicamente está disponible el informe en inglés) ${ }^{5}$.

\section{"Violencia en contra de los niños.}

\section{Tauromaquia}

37. El Comité está preocupado por el bienestar físico y mental de los niños que participan en clases de tauromaquia y las actuaciones asociadas a ella, así como el bienestar mental y emocional de los niños espectadores que están expuestos a la violencia de la tauromaquia.

\footnotetext{
${ }^{5}$ http://www.derechoanimal.info/bbdd/Documentos/1350.pdf http://tbinternet.ohchr.org/Treaties/CRC/Shared\%20Documents/PRT/CRC C PRT CO 3416303 E.pdf
} 
38. El Comité, con miras a la eventual prohibición de la participación de los niños en la tauromaquia, insta al Estado Parte a que adopte las medidas legislativas y administrativas necesarias con el fin de proteger a todos los niños que participan en el entrenamiento y actuaciones de tauromaquia, así como en su calidad de espectadores. Esto puede incluir el aumento de la edad mínima de 12 años para la formación, incluidas las escuelas taurinas y fincas privadas, y para la participación de niños en la tauromaquia, así como un aumentar la edad mínima de 6 años que existe ahora para los niños que pudieron asistir a eventos como espectadores. ${ }^{6}$

El Comité también insta al Estado Parte a que adopte medidas de sensibilización sobre la violencia física y mental asociado a las corridas de toros y su impacto en los niños."

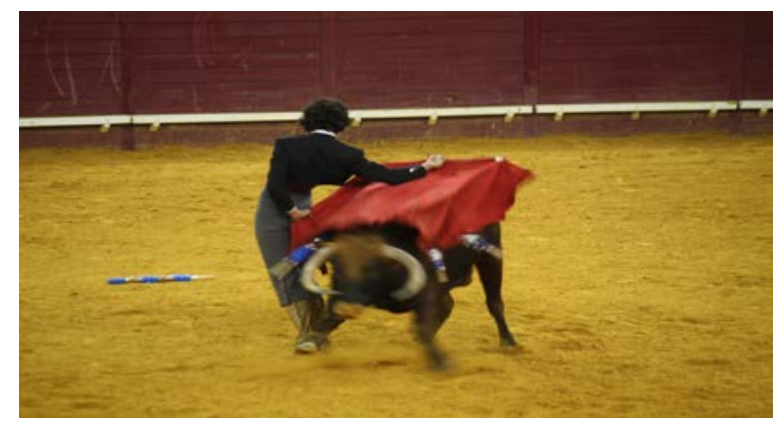

Hay que resaltar que el Comité incluyó dicha observación en el apartado relativo a "Violencia en contra de los niños" -Violence against children (arts.

\footnotetext{
${ }^{6}$ La observación del Comité hace referencia a unas edades teniendo en cuenta la realidad legislativa en ese momento de Portugal, que fija en 12 la participación de niños en eventos taurinos y en 6 la asistencia de niños a espectáculos de tauromaquia. No obstante, la Convención se aplica a los menores de 18 años y no hace distinción alguna respecto a las actividades violentas que como la tauromaquia, según se ha pronunciado el Comité, van en contra del bienestar físico, mental y emocional de los niños.
} 
$19^{7}, 24^{8}$, para. 3,28 , para. $2^{9}, 34,37$ (a) and 39 of the Convention)-, un hecho que refuerza la convicción de que la tauromaquia es una actividad violenta perjudicial para la sociedad. También hay que hacer especial énfasis en el último apartado, conforme al cual, el país tendrá que llevar a cabo campañas de concienciación dirigidas a informar sobre las consecuencias negativas que los espectáculos taurinos provocan en el desarrollo físico, psíquico y moral de los niños.

Para dictar dicho pronunciamiento, el Comité ha tenido en cuenta el interés superior del niño, un principio universal también incorporado en la legislación interna sobre protección de la infancia, en virtud del cual los derechos de los niños prevalecen sobre los demás. Así, la legislación concibe la protección de la infancia y la juventud como un derecho fundamental al que se reconoce y protege, como cuestión prioritaria, primando el interés superior del niño sobre cualquier otro interés legítimo que pudiera concurrir o entrar en conflicto. Teniendo en cuenta que el Comité de los Derechos del Niño considera que los espectáculos taurinos son una actividad violenta perjudicial para el niño, el acceso a esta actividad cultural queda relegado a un plano inferior para obtener la máxima satisfacción de otros derechos prioritarios, como el derecho a su desarrollo físico, mental, moral y emocional. Por este motivo, en este caso, se ha considerado que el interés superior del niño prevalece sobre el de participar libremente en la vida cultural también reconocido en la Convención. Así lo ha

\footnotetext{
7 "Los Estados Partes adoptarán todas las medidas legislativas, administrativas, sociales y educativas apropiadas para proteger al niño contra toda forma de perjuicio o abuso físico o mental, descuido o trato negligente, malos tratos o explotación, incluido el abuso sexual, mientras el niño se encuentre bajo la custodia de los padres, de un representante legal o de cualquier otra persona que lo tenga a su cargo".

8 "Los Estados Partes adoptarán todas las medidas eficaces y apropiadas posibles para abolir las prácticas tradicionales que sean perjudiciales para la salud de los niños".

9 "Los Estados Partes adoptarán cuantas medidas sean adecuadas para velar por que la disciplina escolar se administre de modo compatible con la dignidad humana del niño y de conformidad con la presente Convención".
} 
expresado el Comité en su Observación General no $17(2013)^{10}$ dictada por Naciones Unidas sobre el derecho del niño a las actividades recreativas, la vida cultural y las artes, según la cual "El derecho de los niños a participar libremente en la vida cultural y las artes exige que los Estados partes respeten el acceso de los niños a esas actividades y su libertad de elegirlas y practicarlas, y se abstengan de inmiscuirse en ello, salvo por la obligación de asegurar la protección del niño y la promoción de su interés superior."

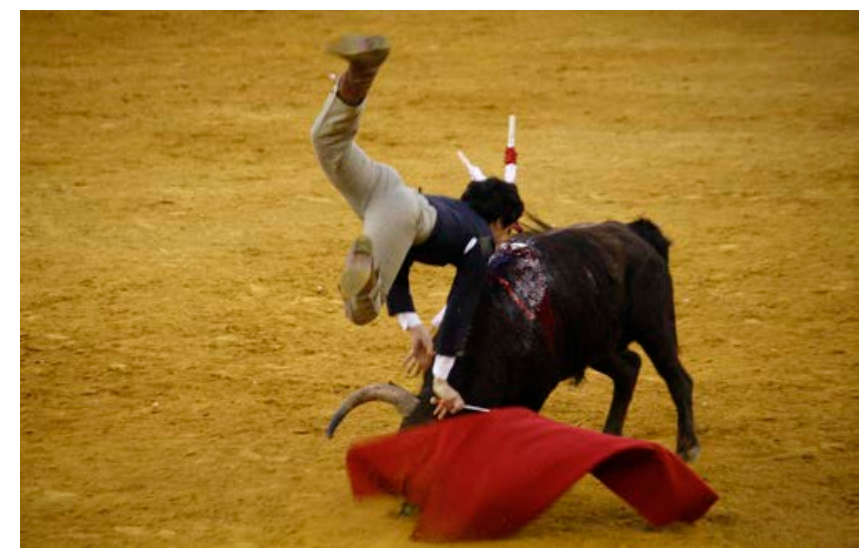

Si bien en el presente caso la solicitud del Comité (recordemos que "El Comité insta a...") va dirigida a Portugal, y por lo tanto, tendrá para plasmar la observación de la ONU en las políticas públicas que se están llevando a cabo en la actualidad para asegurar la implementación de la Convención sobre los Derechos del niño, la actividad sobre la que recae la misma se lleva a cabo en otros países y el criterio del Comité es único, inalterable y permanente, siendo además la primera oportunidad que ha tenido para pronunciarse al respecto en

\footnotetext{
${ }^{10}$ Las observaciones generales son documentos que de forma periódica elabora el Comité de los Derechos del Niño para ayudar a la adecuada interpretación y aplicación de los derechos de la infancia según la Convención de los Derechos del Niño. Se parte de la idea de que la Convención es un documento vivo, cuya aplicación deber ser objeto de constante supervisión, ayudando estos textos a abordar aquellos aspectos sobre los que el Comité_constata falta de la debida atención, interpretaciones erróneas o insuficientes, o bien la necesidad de abordar nuevos aspectos de creciente preocupación.
} 
el examen de un país taurino, por lo que es pronosticable que vaya a pronunciarse de forma equivalente cuando en un futuro próximo el resto de países rindan cuentas ante dicho Comité sobre el cumplimiento de la Convención. Esta circunstancia permite que dichos países, sabiéndose ahora incumplidores de la Convención, anticipen sus acciones para proteger a los niños y así cumplir con la Convención, evitando también una futura declaración internacional del Comité.

Hay que resaltar que todos los Estados Parte mencionados han aprobado leyes que consolidan desde el marco legislativo la Convención de los Derechos del Niño con el fin de garantizar el cumplimiento de los derechos recogidos en dicha Convención. La normativa interna sobre protección de los niños de los países taurinos11 reconocen a los niños el derecho a la integridad personal (que comprende la física, psíquica y la moral) y a disfrutar del nivel más alto posible de salud física y mental, a la educación de calidad y formación integral, al esparcimiento, juegos y demás actividades recreativas propias de su ciclo vital, y a ser protegidos por el Estado, la familia y la sociedad contra_toda forma de violencia física o moral, contra espectáculos inconvenientes para su edad y contra la explotación económica y el desempeño de cualquier trabajo que sea peligroso o nocivo para su salud o para su desarrollo integral.

Por este motivo, las leyes facultan y obligan a los países taurinos a implementar acciones que garanticen la protección de los derechos de los niños, como es la prohibición de participación y asistencia a menores de 18 años en prácticas, espectáculos y eventos de tauromaquia. Así, desde una

\footnotetext{
${ }^{11}$ Colombia: Ley no 1098 - 8/11/2006, por la cual se expide el código de la infancia y la adolescencia Ecuador: Ley no 100-2002/03, por el cual se expide el Código de la Niñez y Adolescencia España: Ley Orgánica 1/1996, de 15 de enero, de Protección Jurídica del Menor Francia: Código Penal (art.227-24).

Portugal: Ley no 147/1999, de protección de los niños y jóvenes en peligro.

Méjico: Ley 29/5/2000, para la Protección de los Derechos de Niñas, Niños y Adolescentes

Perú: Ley $n^{\circ} 27337$, que aprueba el Código de los niños y los adolescentes

Venezuela: Ley Orgánica $n^{\circ}$ 2000-5266, de Protección del Niño y del Adolescente
} 
perspectiva genérica y en su conjunto, dichas medidas legislativas ya contemplan en su articulado la necesidad de garantizar el derecho del niño a que no sea expuesto a la violencia que representan los espectáculos taurinos, por lo que el Poder Ejecutivo -cuya función principal consiste en hacer cumplir las leyes y ejecutar las políticas generales- ya dispone de un mandato legal para hacer efectivo dicho derecho.

No obstante, nada impide que los Estados miembros cumplan con la observación del Comité dictando nueva legislación o modificando la existente. Así, ya sea través de medidas legislativas o administrativas, pueden determinar la edad mínima a 18 años para intervenir en corridas de toros y en cualquier otro espectáculo taurino, como el rejoneo, becerradas, novilladas, toreo cómico, festivales, u otros donde se lidian reses, en calidad de matador de toros, matador de novillos con o sin picadores, rejoneador, banderillero, picador, mozo de espada, puntillero, forcado, así como cualquier otro; prohibir el acceso y asistencia a los espectáculos taurinos a las personas menores de 18 años; prohibir la admisión a personas menores de 18 años a las escuelas taurinas u otro lugar donde se enseñe la tauromaquia; prohibir la emisión de corridas de toros a través de medios audiovisuales privados y públicos durante el horario protegido o de especial protección para la infancia; evitar la promoción o incorporación en el marco del sistema educativo infantil de conocimientos sobre los espectáculos taurinos.

Dicho Comité ha considerado la tauromaquia una actividad violenta a la que se expone al niño desde pequeño vulnerando sus derechos a la integridad física y mental, por lo que ya no existen argumentos que justifiquen amparar legal y administrativamente la participación y asistencia de niños en espectáculos y eventos taurinos. Sin duda, este pronunciamiento de la ONU es un logro muy importante para alejar a los niños de la violencia que representa la tauromaquia, y esperemos que se adopten medidas legislativas, administrativas y educativas en aras a cumplir con la medida internacional para promover y reforzar en los niños del mundo, a los que pertenece el futuro, la 
dA derecho ANIMAL la web center de los animales con derecho

gama de valores éticos concretos consagrados en la Convención sobre los Derechos del Niño, entre ellos la educación para la paz y la no violencia. 